\title{
A Speed Limit on Ice Shelf Collapse through Hydrofracture
}

\author{
Alexander A. Robel ${ }^{1}$, Alison F. Banwell ${ }^{2,3}$ \\ ${ }^{1}$ School of Earth and Atmospheric Sciences, Georgia Institute of Technology
${ }^{2}$ Cooperative Institute for Research in Environmental Sciences, University of Colorado Boulder \\ ${ }^{3}$ Scott Polar Research Institute, University of Cambridge \\ PLEASE NOTE: THIS ARTICLE IS A POSTPRINT OF A PEER-REVIEWED \\ MANUSCRIPT PUBLISHED AT GEOPHYSICAL RESEARCH LETTERS. DOI: \\ 10.1029/2019GL084397.
}

\section{Key Points:}

- Ice shelf melt ponds draining through hydrofracture may influence one another through fracturing

- Localized area of hydrofracture influence limits the speed of ice shelf collapse

- High speed of Larsen B collapse was likely due to anomalously high surface melt, not fracture speed

Corresponding author: Alexander A. Robel, robel@eas.gatech.edu 


\begin{abstract}
Increasing surface melt has been implicated in the collapse of several Antarctic ice shelves over the last few decades, including the collapse of Larsen B Ice Shelf over a period of just a few weeks in 2002. The speed at which an ice shelf disintegrates strongly determines the subsequent loss of grounded ice and sea level rise, but the controls on collapse speed are not well understood. Here we show, using a novel cellular automaton model, that there is an intrinsic speed limit on ice shelf collapse through cascades of interacting melt pond hydrofracture events. Though collapse speed increases with the area of hydrofracture influence, the typical flexural length scales of Antarctic ice shelves ensure that hydrofracture interactions remain localized. We argue that the speed at which Larsen B Ice Shelf collapsed was caused by a season of anomalously high surface meltwater production.
\end{abstract}

\title{
1 Introduction
}

Ice shelves are the floating portions of ice sheets that modulate ice flow towards the ocean. Observations and theory indicate that when an ice shelf disintegrates, the glaciers which previously fed the ice shelf accelerate due to the loss of buttressing back stresses [Scambos et al., 2004; Gudmundsson, 2013]. Ice shelf buttressing stresses which decrease gradually in time, allow for the viscous adjustment of grounded ice, and the maintenance of ice shelf area through increased ice flow into the ice shelf [De Rydt et al., 2015; Minchew et al., 2018]. Conversely, if the ice rheology is sufficiently brittle, rapid removal of an ice shelf may lead to rapid and repeated iceberg fracture and detachment, and significant mass loss where the ice sheet is grounded deep below sea level [Bassis and Walker, 2011; Pollard et al., 2015]. Recent work by Clerc et al. [2019] has shown that ice shelf buttressing must be removed on time scales less than one day to produce rapid brittle fracturing of a nascent subaerial ice cliff at heights attainable in terrestrial ice sheets. The manner and speed at which ice shelves thin and retreat is thus of great consequence for the future of marine ice sheets and sea level rise.

Over the last several decades, surface melting has intensified on ice shelves at progressively more southerly locations on the Antarctic Peninsula [Cook and Vaughan, 2010]. Some ice shelves (e.g., Prince Gustav, Wordie) have thinned and retreated gradually over several decades, while large areas of other ice shelves have disintegrated within a few years. Perhaps the most notable example of such a rapid collapse is Larsen B Ice Shelf (LBIS), which lost most of its area over a period of just a few weeks in 2002 [Sergienko and Macayeal, 2005].

When surface meltwater fills fractures, the added hydrostatic pressure can cause fracture propagation through a process known as hydrofracture [Nye, 1957]. The presence of thousands of melt ponds on LBIS preceding its collapse has led to many theories in which abundant surface melting drives widespread hydrofracture of an ice shelf. These theories include meltwater enhancement of calving through bending near the calving front [Scambos et al., 2009], simultaneous capsize of icebergs generated by throughcutting rifts [MacAyeal et al., 2003], and a chain-reaction of hydrofracture events in closelyspaced melt ponds [Banwell et al., 2013]. In other theories, ice shelves are gradually preweakened by an array of processes (e.g., ocean surface waves, rheological weakening, percolation of water, surface load shifts due to water movement, and basal melting) and then later triggered to collapse within a single melt season [Rack and Rott, 2004; Vieli et al., 2007; Braun and Humbert, 2009; Borstad et al., 2012; Banwell and Macayeal, 2015; Massom et al., 2018; Banwell et al., 2019]. Despite the abundance of theories to explain ice shelf collapse, it remains difficult to build a model of ice shelf collapse because of the large range in spatial and temporal scales that need to be resolved, and the poor understanding of (or lack of equations to describe) many interacting ice shelf processes. 
In this study, we propose (in section 2) a new model of ice shelf collapse that abstracts many poorly-understood processes into a few rules with a minimum of associated parameters, capturing the factors which contribute to the speed and extent of ice shelf collapse through hydrofracture. We also describe the general evolution of the ice shelf as more surface melting occurs, leading to the accumulation of hydrofracture cascades and eventual collapse. In section 3, we discuss what sets the size of hydrofracture cascades and how this sets a speed limit on the rate of ice shelf collapse through hydrofracture. In section 4, we explore how limitation of melt pond depth can prevent ice shelf collapse. Finally, in sections 5 and 6 we discuss the implications of this model for interpreting observations of ice shelf collapse, its relationship to continuous phase transitions in statistical physics, and the prospect for predicting future ice shelf collapse events.

\section{A model of melt pond filling and hydrofracture}

To model ice shelf collapse we use a cellular automaton, an iterative model capturing the behavior of a discrete network of interacting elements. In this cellular automaton, an ice shelf is covered by melt ponds which fill and drain over the course of many model iterations according to simple rules. The ponds (each with index $i$ ) are located at prescribed locations with, on average, one pond per $P$ units of dimensionless ice shelf area. The spatially discretized nature of this model simply reflects the fact that on a rough ice shelf surface, water will tend to collect in depressions producing a spatially-discretized water distribution. There are two evolving dimensionless variables defined at each pond: the water depth, $z$, and the ice strength in the vicinity of the pond, $k$. All melt ponds are initialized in a completely dry $(z=0)$, pristine ice $\left(k=k_{0}\right)$ state (except in section 4). Then, at each iteration, one unit of meltwater depth is added to a random melt pond (where $\bar{w}$ denotes the average water depth added per pond). When a melt pond becomes deep enough to produce hydrostatic pressure exceeding the local material strength of ice (which we simplify to the threshold condition $z \geq k$ ), hydrofracture occurs, draining the entire pond to the ocean and causing damage to nearby ice strength. If the threshold condition is then met on any other nearby pond, the hydrofracture process is repeated until the threshold condition is no longer met at any pond, ending the iteration at a steadystate where no additional hydrofracture occurs without the addition of more water.

The model dynamics described above are simple and can be expressed through a minimal set of rules for each iteration

$$
\begin{aligned}
& \text { (a) } z\left(i_{r}\right) \rightarrow z\left(i_{r}\right)+1 \\
& \text { (b) If } z(i) \geq k(i) \text { and } z(i)>0 \text {, then } \\
& z(i) \rightarrow 0 \\
& k(j) \rightarrow \max [k(j)-D(i, j), 0] \\
& \text { (c) Repeat (b) until } z(i)<k(i) \text { at all } i
\end{aligned}
$$

where $i_{r}$ is a randomly selected melt pond, $j$ is the set of neighboring ponds located within a circular "area of influence" $(A)$ of pond $i$, and $D(i, j)$ is a function that defines how much damage is caused by a hydrofracture event at melt pond $i$ to the ice underlying melt ponds at locations $j$. The average number of ponds damaged by each hydrofracture events is determined by the ratio of area of influence to area per pond, $A / P$. These simple rules reproduce the main features of the hydrofracture process and are conceptually illustrated in Figure 1.

With the addition of enough meltwater, this model of melt pond interactions will always produce eventual ice shelf collapse (which we define as $k \rightarrow 0$ on enough of the ice shelf to render it incapable of transmitting significant stress, see below). Figure 2 shows a representative simulation of ice shelf collapse on a $50 \times 50$ square grid of melt ponds spaced 1 unit of distance apart (i.e. with area per pond $P=1$ ) and $k_{0}=4, D=1$ and $A=1$ (i.e. the neighbors of each pond include the four closest ponds). Figure 2a shows the evolution of mean pond depth and mean ice strength and Figures 2b-d show 


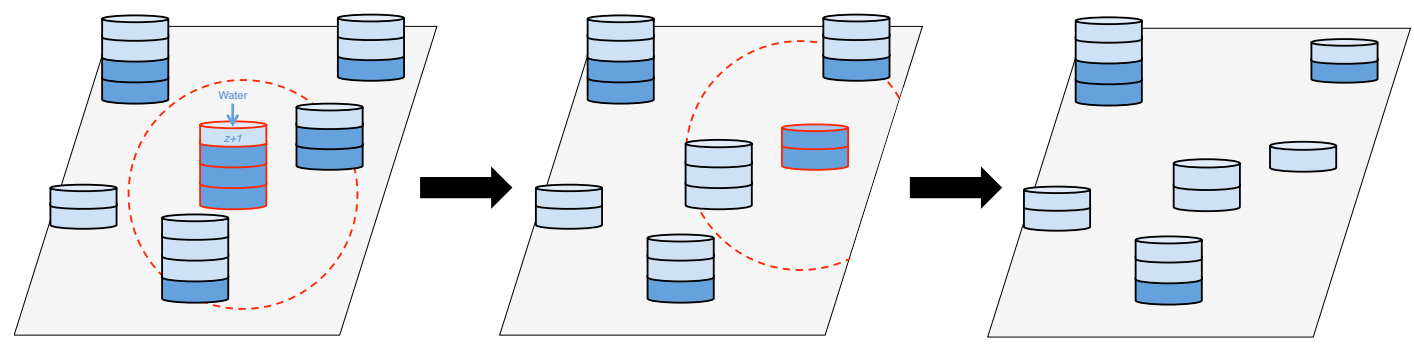

Figure 1. A conceptual schematic illustrating a series of hydrofracture events triggered by the addition of a single unit of meltwater. The height of each cylinder represents the ice strength, $k$, and the number of filled levels of the cylinder (represented by darker blue) represents the melt pond depth, $z$. In the left panel, melt water is added to the red-highlighted pond in the center, bringing it to the threshold for hydrofracture. In the middle panel, the center pond has drained, causing damage to itself and two ponds within its area of influence (red dashed line in left panel). This then brings another lake (highlighted in red in the middle panel) to the threshold for hydrofracture. In the right panel, this pond has drained, leading to further damage to two more nearby ponds. This hypothetical hydrofracture cascade would have a size of $S=2$.

snapshots of the system state (this collapse simulation is also animated in supplementary video $\mathrm{S} 1$ ).

During the the filling stage, melt ponds gradually fill up with meltwater, but mostly remain undamaged and below the local threshold necessary for hydrofracture (Figure $2 \mathrm{~b})$. During this stage, melt pond depths follow a Poisson distribution as the random addition of meltwater in our model is a classical Poisson process. When the mean rate of water drainage through hydrofracture exceeds addition of water through surface melt, the mean water pond depth stops increasing (maximum in Figure 2a), and the hydrofracture stage begins.

During the the hydrofracture stage, the speed at which the ice shelf is being damaged by hydrofracture events rapidly accelerates. Regions of the ice shelf with many melt ponds near the threshold for hydrofracture (Figure 2c) can undergo "hydrofracture cascades", similar to the chain reactions described in Banwell et al. [2013]. In each cascade, the hydrofracture of a single melt pond leads to the damaging of ice underlying "neighbor" ponds, which may then lead to many more hydrofracture events in nearby ponds (as schematized in Figure 1). Once a large fraction of the ice shelf is completely damaged, it is unable to support further hydrofracture cascades, and there is a significant slow down in the loss of ice shelf strength. The ice shelf is heavily damaged in this stage, and is considered collapsed (Figure 2d), since it can no longer transmit significant stresses across the ice shelf, reducing buttressing stresses on upstream grounded ice.

\section{Speed limit on ice shelf collapse}

Hydrofracture cascades are chain reactions of drainage that can rapidly spread across many melt ponds through the influence of one hydrofracture event on nearby ice strength. The size of a hydrofracture cascade is characterized by $S$, the number of melt ponds that are triggered to drain via hydrofracture within that single cascade (which occurs in a single iteration). Figure 3a plots the frequency distribution of $S$ averaged over many model simulations with melt ponds located randomly over a square domain, and a range of values of the damage rate parameter $(D)$ and area of influence $(A)$. In all cases, $S$ displays power law scaling with exponent $\tau=-\frac{3}{2}$ and an exponential cutoff at large $S$. In melt 

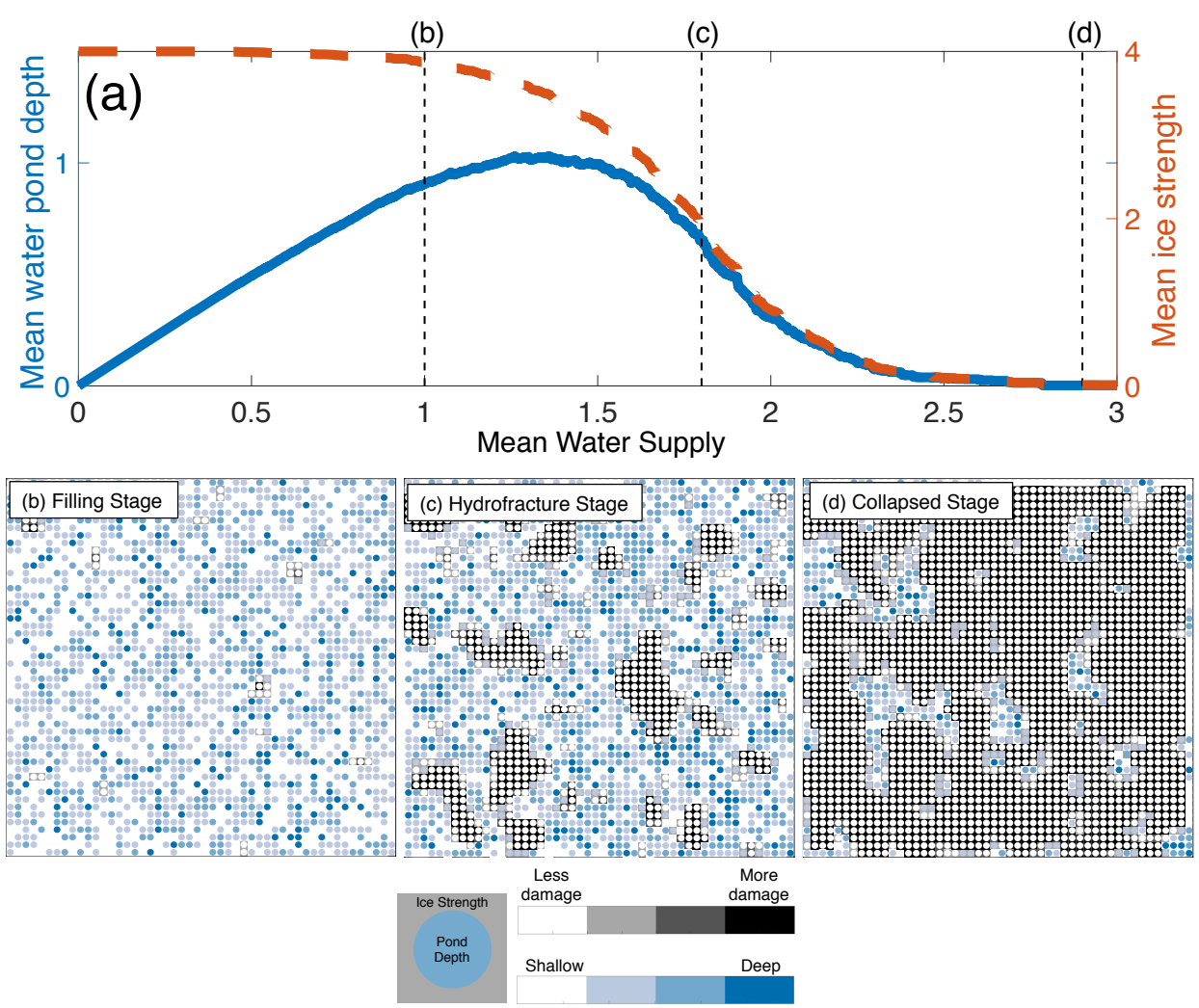

Figure 2. A characteristic simulation of the ice shelf cellular automaton. (a) Evolution of mean water pond depth (blue line; left y-axis) and mean ice strength (red dashed line; right yaxis) as a function of mean water supply (x-axis). All quantities are averaged over all melt pond sites in model domain. Dashed black lines indicate timing of snapshots plotted in panels (b-d). (b-d) Snapshots of model state at three different stages of model evolution: filling stage (panel b), hydrofracture stage (panel c), collapsed stage (panel d). Each snapshot consists of the rectangular grid of melt pond sites, where for each site, the pond depth is indicated by the color of the interior circle and the ice strength is indicated by the color of the surrounding box. Pond depth goes from white (dry) to full (dark blue). Ice strength goes from completely damaged (black) to completely undamaged (white). This simulation is for 2500 melt ponds arranged uniformly on a square domain with $P=1, k_{0}=4, D=1$ and $A=1$, non-periodic boundary conditions, and $10^{4}$ total iterations.

pond networks with more than 100 ponds (simulations not plotted), the size distribution of hydrofracture cascades is independent of the number of ponds in the melt pond network.

As $D$ and $A$ are increased, individual hydrofracture events cause more damage over a larger area, leading to fewer, but larger, hydrofracture cascades (Figure 3a-b). However, since ice strength cannot have values less than zero, there is a limit to the increase in $S$ with $D$, leading all simulations with $D \geq k_{0}$ (where $k_{0}=4$ in these simulations) to have the same $S$ distribution (red and yellow lines in Figure 3a). For the same reason, $S$ is also not strongly sensitive to changes in $k_{0}$ (i.e. increasing $D$ has the same effect as decreasing $k_{0}$ ). Furthermore, the speed of pond filling (i.e. by changing the pond filling increment in equation 1a) only causes changes in the length of the filling stage, but not the hydrofracture stage. In Figure 3d, we measure the speed of ice shelf collapse, 
$v$, by fitting the average rate at which mean ice strength decreases as water is supplied during the hydrofracture stage to: $\bar{k} \propto \tanh (v \bar{w})$. We find that ice shelf collapse speed follows the same pattern as $S$, increasing with greater $D$ and $A$.
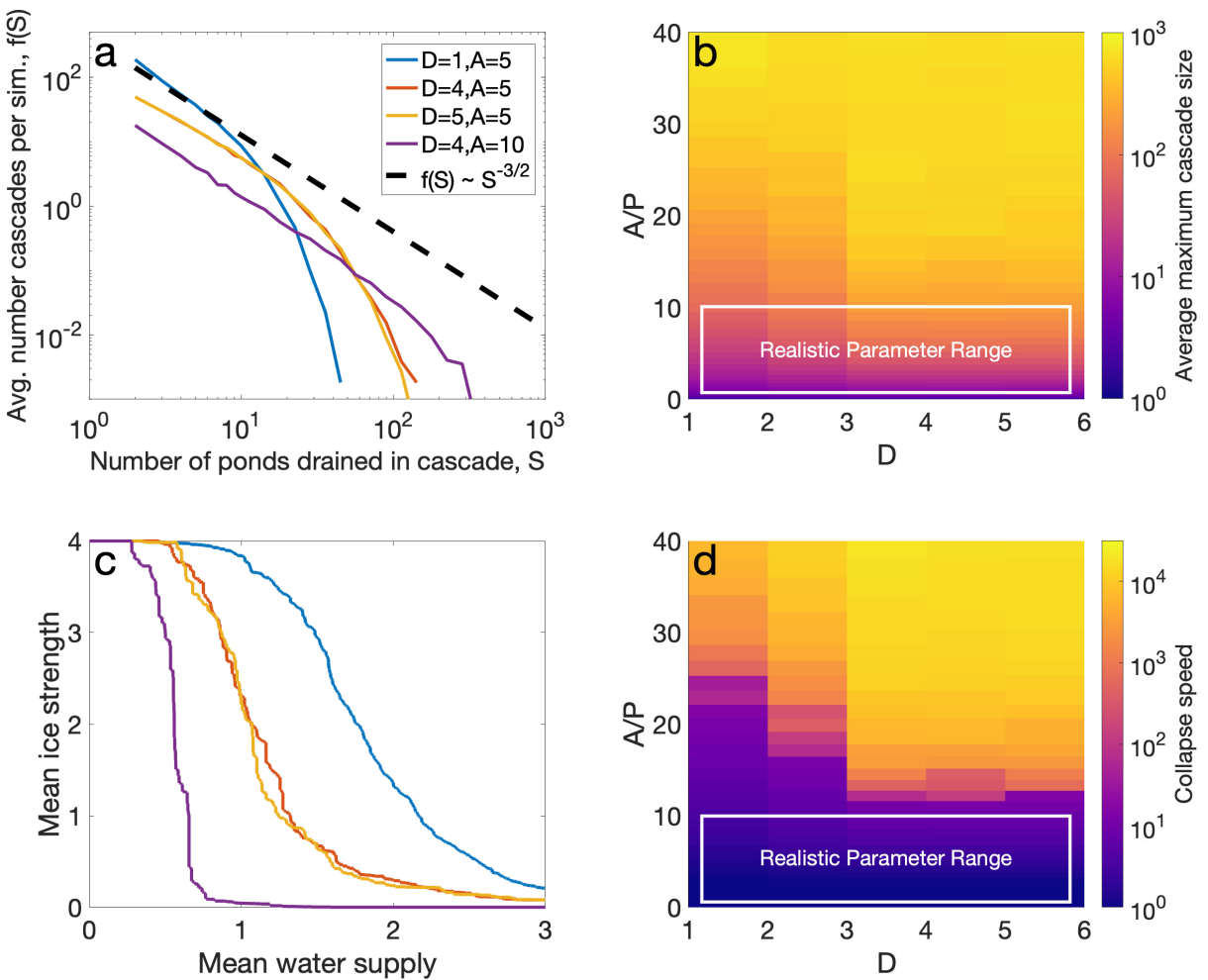

Figure 3. Properties of simulated ice shelf collapse as a function of parameters $D$ and $A$. (a) Number of hydrofracture cascades (y-axis) draining $S$ melt ponds (x-axis) averaged over 100 simulations. Black dashed line is a power law distribution, $f(S) \propto S^{\tau}$, with exponent $\tau=-3 / 2$. (b) Maximum hydrofracture cascade size in a simulation, averaged over 100 simulations. (c) Mean ice strength $(\bar{k})$ evolution as a function of mean water supply $(\bar{w})$ for the same simulations in panel a. (d) Collapse speed, $v$, is defined as the average rate at which mean ice strength decreases during the hydrofracture stage, which is measured by fitting the mean ice strength evolution curves plotted in panel c to $\bar{k} \propto \tanh (v \bar{w})$. As indicated in text, cascades of $O\left(10^{3}\right)$ ponds may produce instantaneous collapse while smaller cascades produce more gradual collapse. In all simulations, 2500 melt ponds are arranged randomly (i.e. each pond location is selected from a uniform distribution within the domain bounds) on a square domain with area 2500 (average area per pond $P=1$ ), with $k_{0}=4$.

A critical result from this model is that the largest hydrofracture cascade size, $S$, that is likely to occur over a wide range of circumstances comparable to observations of melt ponds networks, encompasses somewhere between tens to hundreds of ponds (Figure $3 \mathrm{~b}$ ). The fraction of the ice shelf that can collapse on the rapid fracture time scale (i.e. seconds to days) is set by the size of the largest hydrofracture cascades. Therefore, if the largest hydrofracture cascade likely to occur (for a certain parameter combination) encompasses less than all the ponds on an ice shelf, then many iterations of adding meltwater and triggering hydrofracture cascades are necessary to achieve ice shelf collapse. 
In such a circumstance, there is a lower bound (a "speed limit") on the rate of ice shelf collapse through hydrofracture processes, which is necessarily dependent on the rate of surface melting. Such a speed limit implies that ice shelves cannot collapse arbitrarily quickly through only the positive feedback between nearby hydrofracture events.

Figure 3b shows that rapid collapse (in one iteration) of an ice shelf with 1000 or more ponds by a single hydrofracture cascade will only occur when the ratio of area of pond influence to the average area per pond, $A / P$, is approximately 40 or higher (where $P=1 \mathrm{~km}^{2}$ in our simulations). At the other end of the spectrum, when the area of pond influence is just a few times greater than the average area per pond, our model predicts a gradual reduction in ice shelf size through thousands of small hydrofracture cascades. Such a gradual collapse is similar to studies which find a slow increase in the rate of ice shelf rifting and calving due to surface ice shelf melt over a period of years [MacAyeal et al., 2003; Scambos et al., 2009], though the process described here is a more general positive feedback between meltwater and fracturing. Thus, our model captures the fast and slow end-members of hydrofracture-induced ice shelf collapse, and shows how they are connected primarily through the area of influence.

Though the area of influence depends on the details of ice shelf stress state, rheology, and fracture propagation, we can make a conservatively high estimate of this area under idealized circumstances. When a load is instantaneously removed from an elastic plate, there is a characteristic stress response [Lambeck and Nakiboglu, 1980; MacAyeal and Sergienko, 2013; Banwell et al., 2013], which produces surface tensile stresses within a distance of the load centroid equal to the flexural length scale

$$
L=\left(\frac{E h^{3}}{12\left(1-\nu^{2}\right) \rho_{w} g}\right)^{\frac{1}{4}},
$$

where $E$ is Young's Modulus, $h$ is ice thickness, $\nu$ is Poisson's ratio, $\rho_{w}$ is seawater density and $g$ is acceleration due to gravity. The Nye zero-stress criterion [Nye, 1957] then dictates that surface fractures propagate in regions of finite tensile stress. Therefore, we estimate that within a circular area with radius $L$, propagation of incipient surface fractures will cause damage to ice strength. For Antarctic ice shelves, $h=10-500$ meters, $E=0.5-10 \mathrm{GPa}, \nu=0.3$, and $\rho_{w}=1028 \mathrm{~kg} / \mathrm{m}^{3}$ [Gold, 1977 ; Banwell et al., 2019], giving a range of approximately $0.01-10 \mathrm{~km}^{2}$ for the area of influence. The upper end of this range is a conservatively high estimate for area of influence, given that in reality, two factors would lower the area of influence to a range below $2 \mathrm{~km}^{2}$ : (a) finite ice strength [as known from modern experimental estimates of ice strength; Schulson and Duval, 2009], and (b) estimates of $E$ from observations of ice shelf tidal flexure and the response to pond unloading [Vaughan, 1995; Banwell et al., 2019]. Given the typical area per melt pond on melt-laden ice shelves to be in the range of $0.5-5 \mathrm{~km}^{2}$ [Banwell et al., 2014; Langley et al., 2016], we can estimate that typically $A / P<4$, making it unlikely that hydrofracture cascades will encompass more than 100 ponds, and leading to gradual ice shelf collapse. We may also envision a small hydrofracture cascade causing collapse of an ice shelf with a small network of less than 100 melt ponds, but such a network is likely not capable of densely covering an ice shelf of any appreciable size. We thus conclude that the speed of ice shelf collapse through hydrofracture has an intrinsic limit set by the flexural length scale.

\section{Melt pond capacity and the propensity for ice shelf collapse}

Thus far we have assumed that all ponds in our model are capable of becoming sufficiently deep to initiate drainage through hydrofracture. However, recent observations have found there to be considerable water flow over and off the surface of some ice shelves which may potentially limit the depth of melt ponds [Bell et al., 2017; Kingslake et al., 2017; Macdonald et al., 2018]. Such water flow may occur on steep and/or smooth ice shelves [Banwell, 2017] or due to the erosion of efficient drainage features into the ice 
shelf surface by meltwater [Mantelli et al., 2015; Karlstrom and Yang, 2016]. We test how such processes affect the propensity for ice shelf collapse by setting a maximum depth for each pond, $C(i)$, which we term "capacity". $C$ is a time-invariant parameter drawn from a normal distribution, with mean $\mu_{C}$ and standard deviation $\sigma_{C}=0.1$. Added meltwater (in increments, $\Delta z$, drawn from a normal distribution with mean 1 and standard deviation of 0.1 ) that exceeds the capacity of a given pond is simply drained/removed from the model, without having any affect on the ice. This now changes rule 1a of the cellular automaton model to

$$
\begin{gathered}
\left(\mathrm{a}^{*}\right) \text { If } z\left(i_{r}\right)+\Delta z>C\left(i_{r}\right) \\
z\left(i_{r}\right) \rightarrow z\left(i_{r}\right)
\end{gathered}
$$

In reality, such water is drained to the ocean or ends up in another pond on the ice shelf, however the details of such over-ice water flow are not considered in this study.

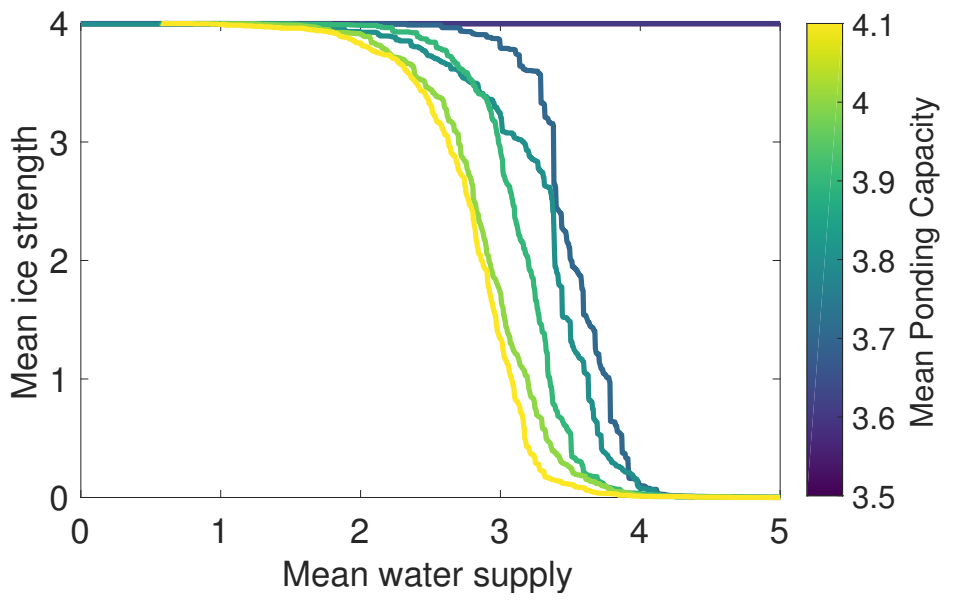

Figure 4. Mean ice strength evolution as a function of water supply, for simulations in which the mean ponding capacity $\left(\mu_{C}\right)$ varies from 3.6 (dark blue) to 4.1 (yellow) and the standard deviation of ponding capacity $\left(\sigma_{C}\right)$ is 0.1 . In these simulations, $D=1$, initial ice strength is selected from a normal distribution with mean $k_{0}=4$ and standard deviation of 0.1 , and the increment of iterative meltwater addition (equation 1a) is also chosen from a normal distribution with mean 1 and standard deviation 0.1 (to go along with the continuous distribution of melt pond capacities). Otherwise model geometry and parameters are the same as in Figure 2, with $10^{4}$ iterations over each simulation.

Figure 4 plots the evolving mean ice strength for a range of simulations with different mean pond capacity, $\mu_{C}$. We find that in simulations where there are no ponds with sufficient capacity to induce hydrofracture $\left(\mu_{C} \leq 3.6\right)$, the ice shelf will never collapse. However, when $\mu_{C}$ becomes sufficiently large that even one pond (out of 2500) can become deep enough to initiate hydrofracture, then the drainage of that one pond will lead to the lowering of nearby pond threshold to below their depth (which is at capacity, $z=C$ ), producing further hydrofracture and ice shelf collapse. When almost all ponds have a capacity that is lower than their initial ice strength, they will fill to capacity which is not sufficient for hydrofracture. Then, when the first hydrofracture event is eventually initiated at one of the few ponds that can deepen enough to hydrofracture, there will be enough nearby ponds at capacity to produce larger hydrofracture cascades. In this regime $\left(3.6<\mu_{C}<3.9\right.$ in Figure 4$)$, ice shelf collapse is delayed (onset at greater mean melt water supply), but is faster than would otherwise occur. When most ponds 
have higher capacity than initial ice strength $\left(\mu_{C} \leq 4\right)$, ice shelf collapse occurs as if capacity were not a factor (as in simulations discussed in sections 2 and 3 ).

\section{Discussion}

The fast processes included in this study are largely similar to (and inspired by) Banwell et al. [2013], which explores the fast hydrofracture response to a prescribed distribution of meltwater on LBIS. In contrast to Banwell et al. [2013], our model does not prescribe a meltwater distribution based on remotely-sensed observations, but iteratively adds water randomly to melt ponds starting from an initially dry ice shelf. Though there are sufficiently few observations of melt pond depth and volume to be able to make strong comparisons to our model, future pond depth data sets (i.e. from ICESat-2) should provide an excellent test of the prediction implicit in our model that pond depths follow a Poisson distribution. One could also envision a version of this model with spatially-constant or smooth meltwater supply and spatially-heterogeneous ice strength from pre-existing fractures, which could be forced by a relatively coarse model of surface melt, though it would still require very high resolution data on ice strength. That possibility notwithstanding, the discretization of surface melt in our model does reflect the observation that there is strong spatial heterogeneity in ice shelf melt rate [Macdonald et al., 2019] and that there is a strong separation of time scales between fast hydrofracture events (i.e. seconds to hours) and the slow filling of melt ponds (i.e. weeks to years). Thus, $\bar{w}$, the amount of meltwater supplied to the model, could be conceptually interchanged with time under the assumption of constant melt rate.

\subsection{Rapid Collapse of Larsen B Ice Shelf}

A speed limit on the rate of hydrofracture-induced ice shelf collapse raises the question of how LBIS was able to collapse over just a few weeks. Given an area per melt pond in the region of densest ponding of LBIS of approximately $1.8 \mathrm{~km}^{2} /$ pond [Banwell et al., 2014], our model suggests that shelf-spanning hydrofracture cascades would require each pond (on average) to cause fracturing in a surrounding area greater than $72 \mathrm{~km}^{2}$ (in order to have $A / P>40)$. Such a large area of influence corresponds to a flexural length scale of greater than $4 \mathrm{~km}$, compared to less than $1.2 \mathrm{~km}$ estimated for LBIS by Banwell et al. [2013] under conservative assumptions. Thus, we conclude it is unlikely that a single or even a few shelf-spanning hydrofracture cascades are responsible for the rapid collapse of LBIS.

The best explanation for the rapid collapse of LBIS is a sudden, widespread surface melt event. To calculate the speed of ice shelf collapse with respect to time, we can consider the shelf-averaged surface melt rate $\left(\frac{d \bar{w}}{d t}\right)$. van den Broeke [2005] found that the surface melt rate on LBIS during the austral summer of 2001/2002 was three times larger than the climatological average due to the persistent advection of warm air over the shelf. Thus, it is plausible and likely, given the evidence, that (a) the 2001/2002 melt season was the first in the modern era in which LBIS experienced sufficient melting (in terms of $\bar{w}$ ) to produce many hydrofracture events [Scambos et al., 2003], and (b) in the 2001/2002 melt season, the very high melt rate caused the ice shelf to proceed through the hydrofracture stage (i.e. trigger many successive or simultaneous small hydrofracture cascades, instead of one large one) in a matter of weeks. Indeed, this includes the possibility that many hydrofracture cascades occur simultaneously. Given the small, compact nature of hydrofracture cascades in our model, such a scenario is not meaningfully different than a very high iterative melt rate (i.e. water supply increases very rapidly). We conclude from the case of LBIS that rapid ice shelf collapse is probably most likely to occur in response to a high rate of surface melt forcing, rather than the internal dynamics of the hydrofracturing melt pond network, which we have shown is speed-limited. 


\subsection{Ice Shelf Collapse as a Continuous Phase Transition}

Our model is similar to the canonical sandpile model first described by Bak et al. [1987], and falls within the general category of chip-firing games on undirected graphs [Björner et al., 1991]. The primary difference between the model in this study and canonical sandpile models is that a hydrofracture event causes a change to nearby threshold values, rather than the variable that triggers the hydrofracture itself. However, by considering the evolution of combined variable $z-k$, one can see that our model resembles a dissipative sandpile model where hydrofracture permanently damages ice in a way that cannot be reversed absent a process which "heals" fractures (or "re-charging" in the parlance of criticality). There is an extensive literature which has shown that dissipative sandpile models have a characteristic cascade (or "avalanche") size that is independent of system size, and which depends in various ways on the model parameters (such as $D$ and $A$ in our model). Even the power law scaling of small hydrofracture cascades $\left(\tau=-\frac{3}{2}\right.$ in Figure 3a) is similar to various other similarly dissipative models [Pruess$n e r, 2012]$, and is indicative of a rapid drop off in cascade size that precludes systemspanning cascades, except on very small or highly-connected graphs. Furthermore, the type of cascade behavior observed in our model is not specific to discretized models, but has also been shown to apply equivalently to versions of the sandpile model with continuousvalued (rather than discrete-valued) quantities [Zhang, 1989; Azimi-Tafreshi et al., 2011].

The hydrofracture stage in our model can be analogized to a continuous phase transition in statistical mechanics [Yeomans, 1992], where the increase in a driving quantity (temperature in thermodynamic systems, meltwater in the ice shelf system) causes a smooth variation in a system state variable (free energy in thermodynamic systems, ice strength in the ice shelf system) towards an absorbing state (a different phase of matter in thermodynamic systems, the collapsed ice shelf in the ice shelf system). Indeed, this connection is perhaps more than simply analogous, as Fey et al. [2010] have proven that dissipative sandpile systems exhibit a continuous phase transition, rather than self-organized criticality for which conservative sandpiles are well-known. In the ice shelf melt pond network, a restoring process, such as fracture healing would be needed to maintain such a self-organized critical system state under increasing surface melt.

\section{Conclusions}

We have found, that except in special circumstances (large hydrofracture area of influence, small melt pond network), rapid ice shelf collapse can only be caused by a correspondingly rapid increase in meltwater production. The fact that almost all examples of ice shelf collapse have occurred over many years (e.g., Prince Gustav, Wordie, George VI ice shelves [Cook and Vaughan, 2010]) likely indicates that the rapid collapse of LBIS represents a special case. However, to determine whether similarly rapid ice shelf collapse over days or weeks is likely to occur at other ice shelves in the future requires a better understanding of the factors which can produce dramatic variability in ice shelf surface melt. To continue to progress towards skillful projections of ice sheet evolution and contribution to sea level rise, future studies should further explore the role of hydrofracture cascades in causing partial or complete ice shelf collapse in more process-rich models of ice shelf hydrology and fracture mechanics. Such models must be forced by climate models of sufficiently high resolution to be capable of capturing the conditions which produce intense surface melt events on ice shelves.

\section{Acknowledgments}

Thanks to K. Wiesenfeld, S. Buzzard, Z. Rashed, F. Clerc, B. Minchew, and D. MacAyeal for discussions and two anonymous reviewers for comments on the manuscript. AAR was supported by NSF PLR-1735715 during part of this work. AFB was supported by a Cooperative Institute for Research in Environmental Sciences (CIRES) Visiting Postdoc- 
toral Fellowship and NSF PLR-1841607 for part of this work. All code used to perform these simulations was written by AAR and is available freely as a public GitHub repository at https://github.com/aarobel/meltpond-cascades.

\section{References}

Azimi-Tafreshi, N., E. Lotfi, and S. Moghimi-Araghi (2011), Continuous abelian sandpile model in two dimensional lattice, International Journal of Modern Physics B, 25(32), 4709-4720.

Bak, P., C. Tang, and K. Wiesenfeld (1987), Self-organized criticality: An explanation of the 1/f noise, Physical review letters, 59(4), 381.

Banwell, A. (2017), Glaciology: Ice-shelf stability questioned, Nature, 544 (7650), 306.

Banwell, A. F., and D. R. Macayeal (2015), Ice-shelf fracture due to viscoelastic flexure stress induced by fill/drain cycles of supraglacial lakes, Antarctic Science, $27(6), 587-597$.

Banwell, A. F., D. R. MacAyeal, and O. V. Sergienko (2013), Breakup of the larsen b ice shelf triggered by chain reaction drainage of supraglacial lakes, Geophysical Research Letters, 40(22), 5872-5876.

Banwell, A. F., M. Caballero, N. S. Arnold, N. F. Glasser, L. Mac Cathles, and D. R. MacAyeal (2014), Supraglacial lakes on the larsen b ice shelf, antarctica, and at paakitsoq, west greenland: a comparative study, Annals of Glaciology, $55(66), 1-8$.

Banwell, A. F., I. C. Willis, G. J. Macdonald, B. Goodsell, and D. R. MacAyeal (2019), Direct measurements of ice-shelf flexure caused by surface meltwater ponding and drainage, Nature communications, 10(1), 730.

Bassis, J., and C. Walker (2011), Upper and lower limits on the stability of calving glaciers from the yield strength envelope of ice, Proceedings of the Royal Society A: Mathematical, Physical and Engineering Sciences, 468(2140), 913-931.

Bell, R. E., W. Chu, J. Kingslake, I. Das, M. Tedesco, K. J. Tinto, C. J. Zappa, M. Frezzotti, A. Boghosian, and W. S. Lee (2017), Antarctic ice shelf potentially stabilized by export of meltwater in surface river, Nature, 544 (7650), 344.

Björner, A., L. Lovász, and P. W. Shor (1991), Chip-firing games on graphs, European Journal of Combinatorics, 12(4), 283-291.

Borstad, C., A. Khazendar, E. Larour, M. Morlighem, E. Rignot, M. Schodlok, and H. Seroussi (2012), A damage mechanics assessment of the larsen b ice shelf prior to collapse: Toward a physically-based calving law, Geophysical Research Letters, 39(18).

Braun, M., and A. Humbert (2009), Recent retreat of wilkins ice shelf reveals new insights in ice shelf breakup mechanisms, IEEE Geoscience and Remote Sensing Letters, 6(2), 263-267.

Clerc, F., B. E. Minchew, and M. D. Behn (2019), Marine ice cliff instability mitigated by slow removal of ice shelves, Geophysical Research Letters, doi: 10.1029/2019GL084183.

Cook, A. J., and D. G. Vaughan (2010), Overview of areal changes of the ice shelves on the antarctic peninsula over the past 50 years., The cryosphere., 4(1), 77-98.

De Rydt, J., G. Gudmundsson, H. Rott, and J. Bamber (2015), Modeling the instantaneous response of glaciers after the collapse of the larsen b ice shelf, Geophysical Research Letters, 42(13), 5355-5363.

Fey, A., L. Levine, and D. B. Wilson (2010), Driving sandpiles to criticality and beyond, Physical review letters, 104 (14), 145,703.

Gold, L. W. (1977), Engineering properties of fresh-water ice, Journal of Glaciology, $19(81), 197-212$. 
Gudmundsson, G. (2013), Ice-shelf buttressing and the stability of marine ice sheets., Cryosphere, 7(2).

Karlstrom, L., and K. Yang (2016), Fluvial supraglacial landscape evolution on the greenland ice sheet, Geophysical Research Letters, 43(6), 2683-2692.

Kingslake, J., J. C. Ely, I. Das, and R. E. Bell (2017), Widespread movement of meltwater onto and across antarctic ice shelves, Nature, $544(7650), 349$.

Lambeck, K., and S. Nakiboglu (1980), Seamount loading and stress in the ocean lithosphere, Journal of Geophysical Research: Solid Earth, 85(B11), 6403-6418.

Langley, E. S., A. A. Leeson, C. R. Stokes, and S. S. Jamieson (2016), Seasonal evolution of supraglacial lakes on an east antarctic outlet glacier, Geophysical Research Letters, 43(16), 8563-8571.

MacAyeal, D. R., and O. V. Sergienko (2013), The flexural dynamics of melting ice shelves, Annals of Glaciology, 54(63), 1-10.

MacAyeal, D. R., T. A. Scambos, C. L. Hulbe, and M. A. Fahnestock (2003), Catastrophic ice-shelf break-up by an ice-shelf-fragment-capsize mechanism, Journal of Glaciology, 49(164), 22-36.

Macdonald, G. J., A. F. Banwell, and D. R. MacAyeal (2018), Seasonal evolution of supraglacial lakes on a floating ice tongue, petermann glacier, greenland, Annals of Glaciology, 59(76pt1), 56-65.

Macdonald, G. J., A. F. Banwell, I. C. Willis, D. P. Mayer, B. Goodsell, and D. R. MacAyeal (2019), Formation of pedestalled, relict lakes on the McMurdo Ice Shelf, Antarctica, Journal of Glaciology, 65(250), 337-343.

Mantelli, E., C. Camporeale, and L. Ridolfi (2015), Supraglacial channel inception: Modeling and processes, Water Resources Research, 51(9), 7044-7063.

Massom, R. A., T. A. Scambos, L. G. Bennetts, P. Reid, V. A. Squire, and S. E. Stammerjohn (2018), Antarctic ice shelf disintegration triggered by sea ice loss and ocean swell, Nature, p. 1.

Minchew, B. M., G. H. Gudmundsson, A. S. Gardner, F. S. Paolo, and H. A. Fricker (2018), Modeling the dynamic response of outlet glaciers to observed ice-shelf thinning in the bellingshausen sea sector, west antarctica, Journal of Glaciology, $64(244), 333-342$.

Nye, J. (1957), The distribution of stress and velocity in glaciers and ice-sheets, in Proceedings of the Royal Society of London A: Mathematical, Physical and Engineering Sciences, vol. 239, pp. 113-133, The Royal Society.

Pollard, D., R. M. DeConto, and R. B. Alley (2015), Potential antarctic ice sheet retreat driven by hydrofracturing and ice cliff failure, Earth and Planetary Science Letters, 412, 112-121.

Pruessner, G. (2012), Self-organised criticality: theory, models and characterisation, Cambridge University Press.

Rack, W., and H. Rott (2004), Pattern of retreat and disintegration of the larsen b ice shelf, antarctic peninsula, Annals of Glaciology, 39, 505-510.

Scambos, T., C. Hulbe, and M. Fahnestock (2003), Climate-induced ice shelf disintegration in the antarctic peninsula, Antarctic Peninsula Climate Variability: Historical and Paleoenvironmental Perspectives, Antarct. Res. Ser, 79, 79-92.

Scambos, T., H. A. Fricker, C.-C. Liu, J. Bohlander, J. Fastook, A. Sargent, R. Massom, and A.-M. Wu (2009), Ice shelf disintegration by plate bending and hydrofracture: Satellite observations and model results of the 2008 wilkins ice shelf break-ups, Earth and Planetary Science Letters, 280(1-4), 51-60.

Scambos, T. A., J. Bohlander, C. Shuman, and P. Skvarca (2004), Glacier acceleration and thinning after ice shelf collapse in the Larsen B embayment, Antarctica, Geophysical Research Letters, 31(18).

Schulson, E. M., and P. Duval (2009), Creep and fracture of ice, Cambridge University Press. 
Sergienko, O., and D. R. Macayeal (2005), Surface melting on larsen ice shelf, antarctica, Annals of Glaciology, 40, 215?218, doi:10.3189/172756405781813474.

van den Broeke, M. (2005), Strong surface melting preceded collapse of antarctic peninsula ice shelf, Geophysical Research Letters, 32(12).

Vaughan, D. G. (1995), Tidal flexure at ice shelf margins, Journal of Geophysical Research: Solid Earth, $100(\mathrm{~B} 4), 6213-6224$.

Vieli, A., A. Payne, A. Shepherd, and Z. Du (2007), Causes of pre-collapse changes of the larsen b ice shelf: Numerical modelling and assimilation of satellite observations, Earth and Planetary Science Letters, 259(3-4), 297-306.

Yeomans, J. M. (1992), Statistical mechanics of phase transitions, Clarendon Press.

Zhang, Y.-C. (1989), Scaling theory of self-organized criticality, Physical Review Letters, 63(5), 470. 